\title{
Documentation of body mass index and control of associated risk factors in a large primary care network Stephanie A Rose*1, Alexander Turchin ${ }^{2}$, Richard W Grant ${ }^{3}$ and James B Meigs 4
}

\author{
Address: ${ }^{1}$ Division of General Internal Medicine, University of Kentucky, 740 South Limestone Street, Kentucky Clinic K507, Lexington, KY 40536, \\ USA, ${ }^{2}$ Clinical Informatics Research and Development, Harvard University, and Division of Endocrinology, Brigham and Women's Hospital, 221 \\ Longwood Avenue, Boston, MA, 02115, USA, ${ }^{3}$ General Medicine Division, Massachusetts General Hospital, 50 Staniford Street, Boston, MA, \\ 02114, USA and ${ }^{4}$ General Medicine Division, Massachusetts General Hospital, 50 Staniford Street, Boston, MA, 02114, USA \\ Email: Stephanie A Rose* - sro226@uky.edu; Alexander Turchin - aturchin@partners.org; Richard W Grant - rgrant@partners.org; \\ James B Meigs - jmeigs@partners.org \\ * Corresponding author
}

Published: 16 December 2009

BMC Health Services Research 2009, 9:236 doi:10.1 186/1472-6963-9-236
Received: 17 May 2009

Accepted: 16 December 2009

This article is available from: http://www.biomedcentral.com//472-6963/9/236

(C) 2009 Rose et al; licensee BioMed Central Ltd.

This is an Open Access article distributed under the terms of the Creative Commons Attribution License (http://creativecommons.org/licenses/by/2.0), which permits unrestricted use, distribution, and reproduction in any medium, provided the original work is properly cited.

\begin{abstract}
Background: Body mass index (BMI) will be a reportable health measure in the United States (US) through implementation of Healthcare Effectiveness Data and Information Set (HEDIS) guidelines. We evaluated current documentation of $\mathrm{BMI}$, and documentation and control of associated risk factors by BMI category, based on electronic health records from a I2-clinic primary care network.

Methods: We conducted a cross-sectional analysis of 79,947 active network patients greater than 18 years of age seen between 7/05 - 12/06. We defined BMI category as normal weight (NW, I8$24.9 \mathrm{~kg} / \mathrm{m}^{2}$ ), overweight (OW, 25-29.9), and obese $(\mathrm{OB}, \geq 30)$. We measured documentation (yes/ no) and control (above/below) of the following three risk factors: blood pressure (BP) $\leq 130 / \leq 85$ $\mathrm{mmHg}$, low-density lipoprotein (LDL) $\leq 130 \mathrm{mg} / \mathrm{dL}$ ( $3.367 \mathrm{mmol} / \mathrm{L})$, and fasting glucose $<100 \mathrm{mg} / \mathrm{dL}$ $(5.55 \mathrm{mmol} / \mathrm{L})$ or casual glucose $<200 \mathrm{mg} / \mathrm{dL}$ (I $1.1 \mathrm{mmol} / \mathrm{L})$.

Results: BMI was documented in 48,376 patients (6I\%, range $34-94 \%)$, distributed as $30 \% \mathrm{OB}, 34 \%$ $\mathrm{OW}$, and $36 \% \mathrm{NW}$. Documentation of all three risk factors was higher in obesity $(\mathrm{OB}=58 \%, \mathrm{OW}$ $=54 \%, \mathrm{NW}=41 \%, \mathrm{p}$ for trend $<0.000 \mathrm{I})$, but control of all three was lower $(\mathrm{OB}=44 \%, \mathrm{OW}=$ $49 \%, \mathrm{NW}=62 \%, \mathrm{p}=0.000 \mathrm{I}$ ). The presence of cardiovascular disease (CVD) or diabetes modified some associations with obesity, and $O B$ patients with CVD or diabetes had low rates of control of all three risk factors (CVD: $O B=49 \%, O W=50 \%, N W=56 \%$; diabetes: $O B=42 \%, O W=47 \%$, $\mathrm{NW}=48 \%, \mathrm{p}<0.000$ I for adiposity-CVD or diabetes interaction).

Conclusions: In a large primary care network BMI documentation has been incomplete and for patients with BMI measured, risk factor control has been poorer in obese patients compared with NW, even in those with obesity and CVD or diabetes. Better knowledge of BMI could provide an opportunity for improved quality in obesity care.
\end{abstract}




\section{Background}

Obesity is a common problem in the United States that independently confers risk for chronic disease and early mortality [1]. Several studies address the importance of recognition and treatment of obesity in chronic disease management, but few evaluate body mass index (BMI) assessment and risk factor documentation and control in patients who are obese both with and without cardiovascular disease (CVD), diabetes or risk factors [2-6].

Assessments of BMI and CVD or diabetes risk factors are simple, inexpensive tools that can be used by primary care physicians (PCPs) to address obesity and its complications. Little consensus exists in current guidelines concerning the need to screen for BMI and associated risk factors [7-15]. In 1998 the National Heart, Lung, and Blood Institute (NHLBI) established guidelines for BMI and risk factor measurement in all patients under 80 years of age with the goal of implementation of strategies for weight loss and risk factor control in patients with a BMI of $\geq 30 \mathrm{~kg} / \mathrm{m}^{2}$ or $25-29.9 \mathrm{~kg} / \mathrm{m}^{2}$ and $\geq$ two risk factors [10]. In 2007 the National Committee for Quality Assurance (NCQA) organized field tests of a prospective Healthcare Effectiveness Data and Information Set (HEDIS) measure to assess the percentage of members $18-74$ years of age with an outpatient visit, and who had BMI documented and risk factors documented if found to have a BMI of $\geq 30$ $\mathrm{kg} / \mathrm{m}^{2}[16]$. Their work led to the proposed HEDIS 2009 measure BMI Assessment [17], which is proposed for reporting by commercial, Medicaid, and Medicare plans.

Given the magnitude and clinical impact of the current obesity epidemic and its risk factors, and the potential implementation of the HEDIS BMI Assessment measure, we aimed to examine current care in BMI and risk factor assessment for patients in a large network of primary care practices that use a common electronic health record (EHR). We investigated the prevalence of BMI measurement and documentation and control of the CVD and diabetes risk factors blood pressure (BP), low density lipoprotein (LDL), and fasting and casual glucose. We examined these risk factors according to the BMI categories normal weight, overweight, and obese. We hypothesized that documentation of BMI would vary widely in clinical practice, and that patients who were obese would be more likely to have better documentation, but poorer control, of risk factors than patients of normal weight.

\section{Methods}

\section{Setting and Patients}

We identified 138,933 patients in our primary care research network of twelve practices that make up the Massachusetts General Hospital Primary Care Practice Based Research Network (PBRN). Practices include urban academic faculty practices, private offices, and commu- nity health centers in and around Boston, Massachusetts. These twelve practices use a common EHR that contains all clinical and utilization data for each patient. The data from the EHR data are searchable in the Research Patient Data Repository (RPDR) [18]. From these, we included 79,947 patients who were at least 18 years of age and had at least two clinic visits billed to their PCP between 7/1/05 and $12 / 31 / 06$, and did not have a height greater than or equal to seven feet (2.13 meters), weight $<70$ or $>1000$ pounds ( $<31.8$ or $>453.6$ kilograms), systolic BP $<50$ or $>260 \mathrm{mmHg}$, or diastolic $\mathrm{BP}<30$ or $>150 \mathrm{mmHg}$. The study was approved by the Partners Health Care System Institutional Review Board.

\section{BMI Measurement}

The intent of the HEDIS initiative is to measure and increase documentation of BMI. We obtained BMI from height and weight data recorded in the EHR, where they are used to automatically calculate and display BMI. For this analysis we calculated BMI from the most recent weight in the 18 -month period and the most recent height prior to $12 / 31 / 06$ from structured coded entries in the EHR. For completeness, we also searched the text of narrative notes in the EHR using a validated Natural Language Processing abstraction tool that computationally abstracts weight, height, and BP values from the free text of clinician notes $[19,20]$. The sensitivity and specificity of the approach to abstraction (compared with a trained chart abstractor) are $87.9 \%$ and $99 \%$ for detection of height, $91.8 \%$ and $92.1 \%$ for detection of weight, and $91 \%$ and $96 \%$ for detection of BP $[19,20]$. Because of high rates of missing heights, we confirmed with clinic site medical directors that we had searched in all the appropriate places in the clincial record for height and weight information.

We categorized BMI using Centers for Disease Control (CDC) definitions, with underweight equal to BMI $<18.5$ $\mathrm{kg} / \mathrm{m}^{2}$, normal weight equal to a BMI of $18.5-<25 \mathrm{~kg} / \mathrm{m}^{2}$, overweight BMI equal to $25-<30 \mathrm{~kg} / \mathrm{m}^{2}$, and obese BMI $\leq 30 \mathrm{~kg} / \mathrm{m}^{2}$ [21]. We included underweight patients when measuring documentation of BMI, but excluded them otherwise. Among those with a documented BMI, we examined documentation and control of three risk factors: blood pressure (BP), LDL cholesterol, and fasting or casual glucose levels, or both. We examined risk factor documentation and control in the clinic population overall, and stratified by three BMI categories.

\section{Risk Factor, CVD, and Diabetes Measurement}

Documentation of a risk factor was defined as being found in the EHR at least once within the study period. If a risk factor was documented more than once, we used the most recently documented value. A risk factor was defined as controlled if within normal range, defined as: $\mathrm{BP} \leq 130 /$ 
$\leq 85 \mathrm{mmHg}, \mathrm{LDL}<130 \mathrm{mg} / \mathrm{dL}(3.367 \mathrm{mmol} / \mathrm{L})$, and fasting glucose $<100 \mathrm{mg} / \mathrm{dL}(5.55 \mathrm{mmol} / \mathrm{L})$ or casual glucose $<200 \mathrm{mg} / \mathrm{dL}$ (11.1 mmol/L) [22-24]. We also measured documentation and control of all three risk factors combined as an aggregate measure of risk factor management.

We defined clinical CVD as coronary artery disease, cerebrovascular accident, or peripheral vascular disease listed on the EHR Problem List, or as having two outpatient or one inpatient International Classification of Diseases, Ninth Revision (ICD-9) codes for CVD. We defined clinical diabetes as diabetes on the EHR problem list and a diabetes medication on the medication list, or as having two outpatient or one inpatient codes related to diabetes. The definitions of diabetes, hypertension, hyperlipidemia and CVD have previously been validated $[25,26]$. For instance, the sensitivity of our approach for diabetes or CVD are $>98 \%$ and specificity of $>97 \%$ compared to the gold standard of trained research nurse chart abstraction. We used the same approach as for diabetes to define hypertension and hyperlipidemia. Other measurements included age, race, gender, number of PCP visits during the study period, insurance type, and clinic site.

\section{Statistical Analysis}

We conducted a cross-sectional analysis. We measured rates of BMI documentation in each clinic site and overall. Among those with a BMI, we measured risk factor documentation and control overall, and stratified by the three BMI categories. We further stratified the analysis by the presence or absence of CVD or diabetes. We used generalized linear models or chi-square tests to test levels or rates of characteristics by BMI category. We used the Breslow Day test for homogeneity of odds ratios to test for effect modification of CVD or diabetes on the association of
BMI with risk factor documentation and control. We used SAS version 9.1 (Cary, NC) for all analyses, and considered a $\mathrm{p}$ value of $<0.05$ to indicate statistical significance.

\section{Results \\ BMI Documentation and Characteristics of Patients with Documented BMI}

Of 79,947 patients, 72,633 (90.9\%) had an available weight, 50,345 (63.0\%) had an available height, and $48,376(60.5 \%)$ had both height and weight recorded to calculate BMI (Table 1). Of those with BMI present, 14,290 patients $(30 \%)$ were classified as obese, 16,402 (34\%) overweight, 16,936 (36\%) normal weight, and 748 (2\%) underweight. Compared to those missing BMI, patients with BMI documented were younger, had a higher mean number of PCP visits, were more likely to be women, and were more likely to have commercial insurance or Medicare than patients without a BMI ( $p<0.0001$ for all; Table 2). As expected, patients with obesity were older, less likely to be women, white, or to have private insurance or Medicare, had a higher mean number of PCP visits, and were more likely to have a history of CVD, diabetes, hypertension, and dyslipidemia than patients of normal weight ( $\mathrm{p}<0.0001$ for all; Table 3$)$.

\section{Documentation and Control of Risk Factors}

Overall, less than $78 \%$ had at least one risk factor documented and just half had all three documented (Table 4, Figure 1). Of these, about half of all patients had all three risk factors controlled (Figure 1). Documentation of all three risk factors was higher in obesity than in overweight or normal weight $(\mathrm{p}<0.0001)$, but control of all three risk factors was lower, $(\mathrm{p}<0.0001)$, with only $44 \%$ of patients with obesity having all risk factors under control.

Table I: Body Mass Index Documentation in 79,947 Patients in 12 Primary Care Clinics

\begin{tabular}{|c|c|c|c|c|}
\hline Clinic & $\mathbf{N}$ & BMI & Height Documented & Weight Documented \\
\hline & & $\%$ & $\%$ & $\%$ \\
\hline I & 3,027 & 93.5 & 94.1 & 99.1 \\
\hline 2 & 4,559 & 89.8 & 95.7 & 91.6 \\
\hline 3 & 3,274 & 86.9 & 87.5 & 99.1 \\
\hline 4 & 3,989 & 85.8 & 94.5 & 87.4 \\
\hline 5 & 1,344 & 75.1 & 75.2 & 99.5 \\
\hline 6 & 7,747 & 65.8 & 66.0 & 99.0 \\
\hline 7 & 21,299 & 64.0 & 65.8 & 96.1 \\
\hline 8 & 3,962 & 55.4 & 55.8 & 98.7 \\
\hline 9 & 12,919 & 50.2 & 55.4 & 71.1 \\
\hline 10 & $4,78 \mid$ & 41.9 & 44.4 & 78.4 \\
\hline II & 8,052 & 38.2 & 38.3 & 99.0 \\
\hline 12 & 4,994 & 34.0 & 35.7 & 88.9 \\
\hline Total & 48,376 & 60.5 & 63.0 & 90.9 \\
\hline
\end{tabular}

Data are ranked by BMI documentation rate, include patients at least 18 years of age with at least two clinic visits billed to their PCP between $7 / \mathrm{I} /$ 05 and $12 / 3 \mathrm{I} / 06$, and include underweight patients $\left(\mathrm{BMI}<18.5 \mathrm{~kg} / \mathrm{m}^{2}\right.$ ) excluded from the main analysis. BMI = Body Mass Index (weight in kilograms/ height in meters ${ }^{2}$ ) 
Table 2: Patient Demographics and Clinical Characteristics in 79,947 Patients in 12 Primary Care Clinics by Documentation or Missingness of BMI

\begin{tabular}{|c|c|c|c|c|c|c|c|}
\hline \multicolumn{3}{|l|}{ Characteristic } & \multirow[t]{2}{*}{ BMI Documented } & \multirow[t]{2}{*}{48,376} & \multirow[t]{2}{*}{ BMI not Documented } & \multirow[t]{2}{*}{$31,57 \mid$} & \multirow{2}{*}{$\begin{array}{l}P \text { value } \\
<0.000 \text { I }\end{array}$} \\
\hline Clinic & $\mathbf{n}$ & $\%$ & & & & & \\
\hline I & & & 2,830 & 5.9 & 197 & 0.6 & \\
\hline 2 & & & 4,093 & 8.5 & 466 & 1.5 & \\
\hline 3 & & & 2,844 & 5.9 & 430 & $\mathrm{I} .4$ & \\
\hline 4 & & & 3,421 & 7.1 & 568 & 1.8 & \\
\hline 5 & & & 1,009 & 2.1 & 335 & I.I & \\
\hline 6 & & & 5,095 & 10.5 & 2,652 & 8.4 & \\
\hline 7 & & & 13,630 & 28.2 & 7,669 & 24.3 & \\
\hline 8 & & & 2,194 & 4.5 & 1,768 & 5.6 & \\
\hline 9 & & & 6,489 & 13.4 & 6,431 & 20.4 & \\
\hline 10 & & & 2,003 & 4.1 & 2,778 & 8.8 & \\
\hline I I & & & 3,073 & 6.4 & 4,979 & 15.8 & \\
\hline 12 & & & 1,696 & 3.5 & 3,298 & 10.5 & \\
\hline Age & \multicolumn{2}{|c|}{ mean years } & 51 & & 53 & & $<0.0001$ \\
\hline Women & $\mathrm{n}$ & $\%$ & 31,412 & 64.9 & 15,986 & 50.6 & $<0.0001$ \\
\hline Race & $\mathrm{n}$ & $\%$ & & & & & $<0.0001$ \\
\hline White & & & 37,625 & 77.8 & 25,264 & 80.0 & \\
\hline Asian & & & 2,057 & 4.3 & 1,426 & 4.5 & \\
\hline Black & & & 2,908 & 6.0 & I,464 & 4.6 & \\
\hline Hispanic & & & 4,123 & 8.5 & 2,397 & 7.6 & \\
\hline Number of PCP visits & mean & range & 4.2 & $(2-61)$ & 3.9 & $(2-56)$ & $<0.000$ I \\
\hline Commercial Insurance or Medicare & $\mathbf{n}$ & $\%$ & 42,740 & 88.4 & 27,522 & 87.2 & $<0.0001$ \\
\hline History of CVD & $\mathbf{n}$ & $\%$ & 7,298 & 15.1 & 4,989 & 15.8 & 0.0060 \\
\hline History of diabetes & $\mathbf{n}$ & $\%$ & 5,872 & 12.1 & 3,453 & 10.9 & $<0.0001$ \\
\hline History of hypertension & $\mathbf{n}$ & $\%$ & 22,121 & 45.7 & 14,698 & 46.6 & 0.02 \\
\hline History of dyslipidemia & n & $\%$ & 25,698 & 53.1 & 17,133 & 54.3 & 0.002 \\
\hline HbAlc & $\%$ & & 6.7 & & 6.8 & & 0.0001 \\
\hline Blood pressure & \multicolumn{2}{|c|}{$\begin{array}{l}\% \\
\text { mean } \mathbf{m m H g}\end{array}$} & $122 / 75$ & & $123 / 74$ & & $<0.0001$ \\
\hline Total cholesterol & \multicolumn{2}{|c|}{ mean $\mathrm{mg} / \mathrm{dL}(\mathrm{mmol} / \mathrm{L})$} & I88.| (4.87) & & $188.5(4.88)$ & & 0.29 \\
\hline LDL & \multicolumn{2}{|c|}{ mean $\mathrm{mg} / \mathrm{dL}(\mathrm{mmol} / \mathrm{L})$} & $104.1(2.70)$ & & $105(2.72)$ & & 0.001 \\
\hline HDL & \multicolumn{2}{|c|}{ mean $\mathrm{mg} / \mathrm{dL}(\mathrm{mmol} / \mathrm{L})$} & $59.3(1.54)$ & & $57.8(1.50)$ & & $<0.0001$ \\
\hline Triglyceride level & \multirow{2}{*}{\multicolumn{2}{|c|}{$\begin{array}{l}\text { mean } \mathrm{mg} / \mathrm{dL}(\mathrm{mmol} / \mathrm{L}) \\
\text { mean } \mathrm{mg} / \mathrm{dL}(\mathrm{mmol} / \mathrm{L})\end{array}$}} & $127.8(1.44)$ & & $132.6(1.50)$ & & $<0.0001$ \\
\hline Casual glucose & & & $101.8(5.65)$ & & $100.8(5.59)$ & & 0.0007 \\
\hline Fasting glucose & \multicolumn{2}{|c|}{ mean $\mathrm{mg} / \mathrm{dL}(\mathrm{mmol} / \mathrm{L})$} & $102.4(5.68)$ & & $100.9(5.60)$ & & 0.0007 \\
\hline Risk factor documentation & Total n & $\%$ & & & & & \\
\hline Blood Pressure & 64,204 & 80.3 & 37,489 & 77.5 & 26,715 & 84.6 & $<0.0001$ \\
\hline LDL & 55,210 & 69.1 & 33,788 & 69.8 & 21,422 & 67.9 & $<0.0001$ \\
\hline Casual glucose & 56,984 & 71.3 & 35,125 & 72.6 & 21,859 & 69.2 & $<0.0001$ \\
\hline Fasting glucose & 21,533 & 26.9 & 13,533 & 28.0 & 8,000 & 25.3 & $<0.0001$ \\
\hline HbAlc & 14,252 & 17.8 & 9,367 & 19.4 & 4,885 & 15.5 & $<0.0001$ \\
\hline Total cholesterol & 58,951 & 73.7 & 36,247 & 74.9 & 22,704 & 71.9 & $<0.0001$ \\
\hline HDL & 58,373 & 73.0 & 35,874 & 74.2 & 22,499 & 71.3 & $<0.0001$ \\
\hline Triglycerides & 55,948 & 70.0 & 34,247 & 70.8 & 21,701 & 68.7 & $<0.0001$ \\
\hline $\begin{array}{l}\text { Risk factor control in those with } \\
\text { documented risk factor }\end{array}$ & Total n & $\%$ & & & & & \\
\hline $\begin{array}{l}\text { Blood Pressure }<130 \text { and }<85 \\
\mathrm{mmHg}\end{array}$ & 46,748 & 72.8 & 27,212 & 72.6 & 19,536 & 73.1 & 0.13 \\
\hline LDL $<130 \mathrm{mg} / \mathrm{dL}$ & 43,369 & 78.6 & 26,656 & 78.9 & 16,713 & 78.0 & 0.015 \\
\hline Casual glucose $<200 \mathrm{mg} / \mathrm{dL}$ & 55,642 & 97.6 & 34,231 & 97.5 & 21,411 & 98.0 & 0.0001 \\
\hline Fasting glucose $<100 \mathrm{mg} / \mathrm{dL}$ & 13,782 & 64.0 & 8,574 & 63.4 & 5,208 & 65.1 & 0.01 \\
\hline HbA I c $<7 \%$ & 9,638 & 67.6 & 6,463 & 69.0 & 3,175 & 65.0 & $<0.0001$ \\
\hline Total cholesterol $<200$ mg/dL & 37,279 & 63.2 & 22,952 & 63.3 & 14,327 & 63.1 & 0.59 \\
\hline $\begin{array}{l}\mathrm{HDL}>35 \mathrm{mg} / \mathrm{dL} \text { (male) and >40 } \\
\mathrm{mg} / \mathrm{dL} \text { (female) }\end{array}$ & 52,971 & 90.8 & 32,742 & 91.3 & 20,229 & 89.9 & $<0.0001$ \\
\hline Triglycerides $<150 \mathrm{mg} / \mathrm{dL}$ & 48,188 & 86.1 & 29,675 & 86.7 & 18,513 & 85.3 & $<0.0001$ \\
\hline
\end{tabular}

P-value compares BMI documented with BMI not documented. BMI = Body Mass Index (weight in kilograms/height in meters ${ }^{2}$ ), $\mathrm{PCP}=\mathrm{Primary}$ Care Physician, $C V D=$ Cardiovascular Disease, $\mathrm{HbAI}=$ Hemoglobin AIC, LDL=low density lipoprotein cholesterol, $\mathrm{HDL}=$ high density lipoprotein cholesterol. $\mathrm{LDL}<130 \mathrm{mg} / \mathrm{dL}=<3.367 \mathrm{mmol} / \mathrm{L}$; casual glucose $<200 \mathrm{mg} / \mathrm{dL}=<5.55 \mathrm{mmol} / \mathrm{L}$; fasting glucose $<100 \mathrm{mg} / \mathrm{dL}=<11.1 \mathrm{mmol} / \mathrm{L}$ 
The presence of CVD or diabetes modified some associations of BMI category with risk factor documentation and control. In patients with CVD or diabetes, the rates of documentation were generally less different comparing patients with obesity with those of normal weight, while in patients without CVD or diabetes, rates of documentation were strikingly higher in patients with obesity than normal weight (Figure 1, Table 5, p $=0.26$ to $<0.0001$ for CVD- or diabetes-by-BMI category interaction). Likewise, in patients with CVD or diabetes the rates of control were generally less different comparing patients with obesity with those with normal weight, but in patients without CVD or diabetes, rates of control were strikingly lower in patients with obesity than normal weight (Figure 1, Table 6 ). Overall $50 \%$ or fewer of the patients with obesity and CVD or diabetes had all three risk factors under control (Figure 1, Tables 5 and 6).

\section{Discussion}

We examined the current state of BMI documentation and documentation and control of associated risk factors by BMI category, based on EHR data from almost 80,000 adult patients seen in a 12-clinic primary care network during 18 months in 2005-2006. Our findings demonstrate variations in risk factor recognition and control for obese persons compared to those of normal weight, as well as for those with and without CVD or type 2 diabetes. We found that documentation of BMI varied widely by clinic site and was overall low. Among patients with a BMI recorded, documentation of most risk factors was higher in patients with obesity compared with normal weight patients; however, control of risk factors was poorer in obesity than normal weight. Patients without a documented history of CVD or diabetes had strikingly more dissimilar rates of documentation and control between weight categories than patients with CVD or diabetes. Overall, patients with obesity with or without CVD or dia- betes had lower rates of risk factor documentation and control than may be ideal given their high absolute risk of adverse health outcomes.

Our study builds upon findings from previous studies. Lemay et al audited medical records from 465 adult patients seen at a community health center during one week in February of 1999 to evaluate height and weight documentation and obesity diagnosis by the practitioner over a prior six-month period, and found that only $63 \%$ of their patient cohort had a height and weight documented [27]. Similar to our study, Lemay looked a group of patients in normal clinical practice; however, we were able to expand upon this study in terms of a far larger study sample as well as a longer sampling frame to assess provision of services (18 months versus 6 months), potentially providing a more accurate picture of risk factor evaluation. Six years after this study and seven years after the establishment of the NHLBI guidelines, we found the percentage of BMI documentation to be essentially the same $(63 \%$ versus $60.5 \%)$. Rifas-Shiman et al studied 5,025 members of the same insurance plan and group practice who were a subset of participants from a cohort study and were continuously enrolled since 1999, had a visit in 2000, had a BMI measurement between January 1 , 2000 and December 31, 2000, and who did not have medical conditions related to weight loss or CVD. They found that higher BMI was an independent predictor of increased fasting glucose, triglyceride, LDL cholesterol, and HDL cholesterol screening [28]. Rifas-Shiman identified lipid and glucose abnormalities over a two-year period, comparable in time to our study. Neither we nor Rifas-Shiman could evaluate attempts at management, so reasons for increased documentation such as guideline adherence could not be assessed. Our analysis extends prior studies by evaluating whether those with documentation of risk factors had those risk factors in control

Table 3: Characteristics of 47,628 Primary Care Patients by BMI Category

\begin{tabular}{|c|c|c|c|c|c|c|c|c|}
\hline Characteristic & & Obese & $n=14,290$ & Overweight & $n=16,402$ & Normal & $n=16,936$ & $P$ value \\
\hline Age & (mean years) & & 53 & 5 & & & 48 & $<0.0001$ \\
\hline Number of $P C P$ visits & (mean) & & 4.7 & 4. & & & 3.9 & $<0.0001$ \\
\hline Women & n (\%) & 8,565 & 59.9 & 8,899 & 54.3 & 13,272 & 78.4 & $<0.0001$ \\
\hline Race* & n (\%) & & & & & & & $<0.0001$ \\
\hline White & & 10,712 & 75.0 & 12,674 & 77.3 & 13,655 & 80.6 & \\
\hline Asian & & 179 & 1.3 & 567 & 3.5 & 1,229 & 7.3 & \\
\hline Black & & 1,244 & 8.7 & 989 & 6.0 & 649 & 3.8 & \\
\hline Hispanic & & 1,722 & 12.1 & $|, 56|$ & 9.5 & 811 & 4.8 & \\
\hline Private Insurance or Medicare & n (\%) & 12,104 & 84.7 & 14,502 & 88.4 & 15,467 & 91.3 & $<0.0001$ \\
\hline History of CVD & n (\%) & 2,647 & 18.5 & 2,699 & 16.5 & 1,862 & 11.0 & $<0.0001$ \\
\hline History of diabetes & n (\%) & 3,238 & 22.7 & 1,789 & 10.9 & 824 & 4.9 & $<0.0001$ \\
\hline History of hypertension & n (\%) & 9,116 & 63.8 & 7,895 & 48.1 & 4,931 & 29.1 & $<0.0001$ \\
\hline History of dyslipidemia & n (\%) & 9,235 & 64.6 & 9,495 & 57.9 & 6,769 & 40.0 & $<0.0001$ \\
\hline
\end{tabular}

$\mathrm{P}$-value is for general association across BMI categories. $\mathrm{BMI}=$ Body Mass Index (weight in kilograms/height in meters ${ }^{2}$ ), $\mathrm{PCP}=\mathrm{Primary}$ Care

Physician, and CVD = Cardiovascular Disease. *Designation "Other" for race deleted from set. 
Table 4: Documentation and Control of Risk Factors among 47,628 Primary Care Patients, by BMI Category

\begin{tabular}{|c|c|c|c|c|c|c|c|c|c|}
\hline Risk Factor Documentation & Total & $n=47,628$ & Obese & $n=14,290$ & Overweight & $n=16,402$ & Normal & $n=16,936$ & $P$ value \\
\hline & $\mathbf{n}$ & $\%$ & $\mathbf{n}$ & $\%$ & $\mathbf{n}$ & $\%$ & $\mathbf{n}$ & $\%$ & \\
\hline BP & 36,934 & 77.6 & 10,900 & 76.3 & 12,890 & 78.6 & 13,144 & 77.6 & $<0.0001$ \\
\hline LDL & 33,427 & 70.2 & 11,239 & 78.7 & 12,013 & 73.2 & 10,175 & 60.1 & $<0.0001$ \\
\hline Casual Glucose & 34,589 & 72.6 & 11,216 & 78.5 & 11,901 & 72.6 & 11,472 & 67.7 & $<0.0001$ \\
\hline Fasting Glucose & $|3,42|$ & 28.2 & 5,347 & 37.4 & 4,804 & 29.3 & 3,270 & 19.3 & $<0.0001$ \\
\hline \multirow[t]{2}{*}{ Risk Factor Control } & \multicolumn{2}{|c|}{ Total } & \multicolumn{2}{|c|}{ Obese } & \multicolumn{2}{|c|}{ Overweight } & \multicolumn{2}{|c|}{ Normal } & $P$ value \\
\hline & $\mathbf{n}$ & $\%$ & $\mathbf{n}$ & $\%$ & $\mathbf{n}$ & $\%$ & $\mathbf{n}$ & $\%$ & \\
\hline BP $<130$ and $<85 \mathrm{mmHg}$ & 26,736 & 72.4 & 6,801 & 62.4 & 9,202 & 71.4 & 10,733 & 81.7 & $<0.0001$ \\
\hline LDL $<130 \mathrm{mg} / \mathrm{dL}$ & 26,328 & 78.8 & 8,777 & 78.1 & 9,273 & 77.2 & 8,278 & 81.4 & $<0.0001$ \\
\hline Casual glucose $<200 \mathrm{mg} / \mathrm{dL}$ & 33,698 & 97.4 & 10,707 & 95.5 & 11,635 & 97.8 & 11,356 & 99.0 & $<0.0001$ \\
\hline Fasting glucose $<100 \mathrm{mg} / \mathrm{dL}$ & 8,482 & 63.2 & 2,753 & 51.5 & 3,146 & 65.5 & 2,583 & 79.0 & $<0.0001$ \\
\hline
\end{tabular}

P-value is for general association across BMI categories. BMI=Body Mass Index (weight in kilograms/height in meters ${ }^{2}$ ); LDL $<130 \mathrm{mg} / \mathrm{dL}=<3.367$ $\mathrm{mmol} / \mathrm{L}$; casual glucose $<200 \mathrm{mg} / \mathrm{dL}=<5.55 \mathrm{mmol} / \mathrm{L}$; fasting glucose $<100 \mathrm{mg} / \mathrm{dL}=<11.1 \mathrm{mmol} / \mathrm{L}$.

according to Adult Treatment Panel III (ATP III) metabolic syndrome guidelines for a patient with average cardiovascular risk.

Molenaar et al studied rates of treatment and control of hypercholesterolemia, hypertension, and diabetes in normal weight, overweight, and obese subjects with a history of these conditions utilizing a CVD-free subset of the Framingham Heart Study. They found that subjects with hypercholesterolemia and hypertension who were obese were more likely to have these conditions treated than normal weight subjects. Rates of control of hypertension and hypercholesterolemia were uniformly poor and did not differ between weight groups. Rates of control of diabetes were poor among all three weight groups, but subjects who were obese were less likely to have control of fasting blood glucose than normal weight subjects. The goal of our study, however, was different from that of Molenaar. Molenaar studied rates of treatment and control of hypercholesterolemia, hypertension, and diabetes in normal weight, overweight, and obese subjects with a history of these conditions who were free of CVD, a subgroup of patients with a clear indication for BMI screening. Our goal was to evaluate in all patients, both with and without obesity-associated risk factors, the current state of BMI screening and subsequent screening for associated risk factors by BMI group, according to HEDIS and NHLBI guidelines. Molenaar et al examined a well-known, standardized study population, where only 196 subjects had missing BMI data. Our population was a non-standardized data source, and our subjects were a mixture of both those with and without CVD and its risk factors, with further subanalysis in patients with a history of CVD and diabetes. Despite these differences, findings from the structured Framingham population and from our analysis of usual clinical care are strikingly similar. This minimizes to a large degree the concern that high rates of missing BMI information could have distorted our findings, and may explain why our percentages of control were higher than those found by Molenaar, albeit still low overall [29].

The rapidly growing prevalence of obesity has pushed BMI assessment to appropriate prominence as a newly proposed reportable HEDIS measure. BMI assessment will be made by several means, including survey of EHRs in health care networks. Our results suggest that the HEDIS BMI Assessment measure has potential to provide a timely quality and safety foundation to improve care for patients with obesity. At least in our large primary care network, there clearly is substantial room for improvement in documentation of BMI and documentation and control of BMI-associated risk factors. While height and weight and BMI documentation may reflect individual physician practice styles, by speaking with medical directors we found that lack of height and weight appeared to be a clinic-level and not an individual PCP issue, with height and weight recording often performed or not performed before the PCP sees the patient. It is expected that introduction of the HEDIS BMI Assessment measure will improve this state of affairs, although the effectiveness of $\mathrm{BMI}$ documentation alone to improve care remains to be demonstrated.

According to our study, patients with already documented CVD or diabetes are more likely to have risk factor documentation and control regardless of BMI category. Those without a documented history of CVD or diabetes demon- 

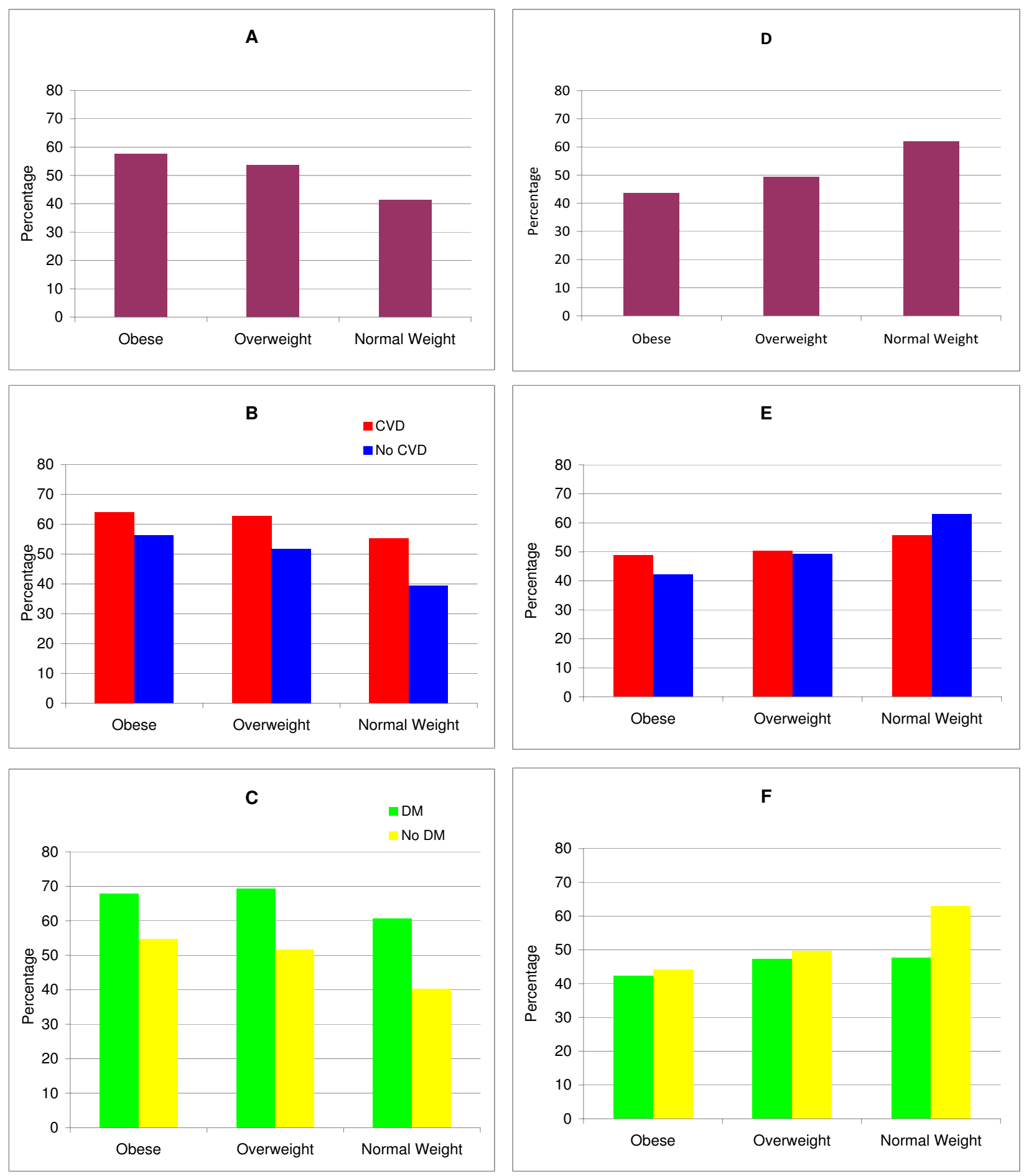

\section{Figure I}

Documentation and control of all three risk factors by BMI category. A. Documentation of all 3 risk factors by BMI category; B. Documentation of all 3 risk factors by BMI category, stratified by history of CVD; C. Documentation of all 3 risk factors by BMI category, stratified by history of diabetes. D. Control of all 3 risk factors by BMI category; E. Control of all 3 risk factors by BMI category, stratified by history of CVD; F. Control of all 3 risk factors by BMI category, stratified by history of diabetes. 
Table 5: Documentation of Risk Factors in 47,628 Patients in I 2 Primary Care Clinics Stratified by BMI Category and History of CVD or Diabetes

\begin{tabular}{|c|c|c|c|c|c|c|c|c|c|}
\hline Risk Factors & Tot & & Obese & $n=14,290$ & Overweight & $n=16,402$ & $\begin{array}{l}\text { Normal } \\
\text { Weight }\end{array}$ & $n=16,936$ & $P$ value \\
\hline $\begin{array}{l}\text { History of } \\
\text { CVD }\end{array}$ & $\mathbf{n}$ & $\%$ & $\mathbf{n}$ & $\%$ & $\mathbf{n}$ & $\%$ & $\mathbf{n}$ & $\%$ & \\
\hline $\begin{array}{l}\text { H/O CVD n } \\
=7,208\end{array}$ & & & \multicolumn{2}{|c|}{$\mathrm{H} / \mathrm{O}$ CVD N = 2,647 } & \multicolumn{2}{|c|}{ H/O CVD N = 2,699 } & \multicolumn{2}{|c|}{ H/O CVD N = I,862 } & \\
\hline $\begin{array}{l}\text { NO H/O } \\
\text { CVD } n= \\
40,420\end{array}$ & & & \multicolumn{2}{|c|}{ No $H / O$ CVD $N=11,643$} & \multicolumn{2}{|c|}{ NO H/O CVD N = 13,703 } & \multicolumn{2}{|c|}{ NO H/O CVD $N=15,074$} & \\
\hline BP & & & \multicolumn{2}{|c|}{$n=10,900$} & \multicolumn{2}{|c|}{$n=12,890$} & \multicolumn{2}{|c|}{$n=13,144$} & \\
\hline H/O CVD & 5,297 & 73.5 & 1,931 & 73.0 & $|, 99|$ & 73.8 & 1,375 & 73.9 & 0.26 \\
\hline $\begin{array}{l}\text { NO H/O } \\
\text { CVD }\end{array}$ & 31,637 & 78.3 & 8,969 & 77.0 & 10,899 & 79.5 & 11,769 & 78.1 & \\
\hline LDL & & & \multicolumn{2}{|c|}{$n=11,239$} & \multicolumn{2}{|c|}{$n=12,013$} & \multicolumn{2}{|c|}{$n=10,175$} & \\
\hline H/O CVD & 6,199 & 86.0 & 2,393 & 90.4 & 2,358 & 87.4 & $\mathrm{I}, 448$ & 77.8 & 0.15 \\
\hline $\begin{array}{l}\text { NO H/O } \\
\text { CVD }\end{array}$ & 27,228 & 67.4 & 8,846 & 76.0 & 9,655 & 70.5 & 8,727 & 57.9 & \\
\hline Casual glucose & & & \multicolumn{2}{|c|}{$n=11,216$} & \multicolumn{2}{|c|}{$n=|I, 90|$} & \multicolumn{2}{|c|}{$n=11,472$} & \\
\hline H/O CVD & 6,305 & 87.5 & 2,355 & 89.0 & 2,322 & 86.0 & 1,628 & 87.4 & 0.0001 \\
\hline $\begin{array}{l}\text { NO H/O } \\
\text { CVD }\end{array}$ & 28,284 & 70.0 & 8,861 & 76.1 & 9,579 & 69.9 & 9,844 & 65.3 & \\
\hline $\begin{array}{l}\text { Fasting } \\
\text { glucose }\end{array}$ & & & \multicolumn{2}{|c|}{$n=5,347$} & \multicolumn{2}{|c|}{$n=4,804$} & \multicolumn{2}{|c|}{$n=3,270$} & \\
\hline H/O CVD & 2,741 & 38.0 & $\mathrm{I}, 158$ & 43.8 & 1,023 & 37.9 & 560 & 30.1 & $<0.0001$ \\
\hline $\begin{array}{l}\text { NO H/O } \\
\text { CVD }\end{array}$ & 10,680 & 26.4 & 4,189 & 36.0 & 3,781 & 27.6 & 2,710 & 18.0 & \\
\hline $\begin{array}{l}\text { All } 3 \text { risk } \\
\text { factors }\end{array}$ & & & \multicolumn{2}{|c|}{$n=8,247$} & \multicolumn{2}{|c|}{$n=8,797$} & \multicolumn{2}{|c|}{$n=6,986$} & \\
\hline H/O CVD & 4,417 & 61.3 & 1,696 & 64.1 & 1,693 & 62.7 & $\mathrm{I}, 028$ & 55.2 & $<0.0001$ \\
\hline $\begin{array}{l}\text { NO H/O } \\
\text { CVD }\end{array}$ & 19,613 & 48.5 & 6,551 & 56.3 & 7,104 & 51.8 & 5,958 & 39.5 & \\
\hline History of DM & & & $\mathrm{n}$ & $\%$ & $\mathrm{n}$ & $\%$ & $\mathrm{n}$ & $\%$ & \\
\hline $\begin{array}{l}\mathrm{H} / \mathrm{O} \\
\text { diabetes } \mathrm{n}= \\
5,85 \mathrm{I}\end{array}$ & & & \multicolumn{2}{|c|}{$\mathrm{H} / \mathrm{O}$ diabetes $\mathrm{N}=3,238$} & \multicolumn{2}{|c|}{$\mathrm{H} / \mathrm{O}$ diabetes $\mathrm{N}=1,789$} & \multicolumn{2}{|c|}{$\mathrm{H} / \mathrm{O}$ diabetes $\mathrm{N}=\mathbf{8 2 4}$} & \\
\hline $\begin{array}{l}\text { NO H/O } \\
\text { diabetes } \\
n=41,777\end{array}$ & & & \multicolumn{2}{|c|}{$\begin{array}{c}\text { NO } H / O \text { diabetes } N= \\
11,052\end{array}$} & \multicolumn{2}{|c|}{ NO $\mathrm{H} / \mathrm{O}$ diabetes $N=14,613$} & \multicolumn{2}{|c|}{$\begin{array}{c}\text { NO } H / O \text { diabetes } N= \\
16,112\end{array}$} & \\
\hline BP & & & \multicolumn{2}{|c|}{$n=10,900$} & $\mathbf{n}=\mathbf{I}$ & 890 & $\mathbf{n}=1$ & 144 & \\
\hline $\begin{array}{l}\mathrm{H} / \mathrm{O} \\
\text { diabetes }\end{array}$ & 4,398 & 75.2 & 2,447 & 75.6 & 1,366 & 76.4 & 585 & 71.0 & 0.002 \\
\hline $\begin{array}{l}\text { NO H/O } \\
\text { diabetes }\end{array}$ & 32,536 & 77.9 & 8,453 & 76.5 & 11,524 & 78.9 & 12,559 & 78.0 & \\
\hline LDL & & & &, 239 & $\mathbf{n}=\mathbf{I}$ & 013 & $\mathbf{n}=1$ & 175 & \\
\hline $\begin{array}{l}\mathrm{H} / \mathrm{O} \\
\text { diabetes }\end{array}$ & 5,285 & 90.3 & 2,963 & 91.5 & 1,617 & 90.4 & 705 & 86.2 & 0.51 \\
\hline $\begin{array}{l}\text { NO H/O } \\
\text { diabetes }\end{array}$ & 28,142 & 67.4 & 8,276 & 74.9 & 10,396 & 71.1 & 9,470 & 58.8 & \\
\hline Casual glucose & & & & 1,216 & $\mathbf{n}=\mathbf{I}$ & 901 & $\mathbf{n}=1$ & 472 & \\
\hline $\begin{array}{l}\mathrm{H} / \mathrm{O} \\
\text { diabetes }\end{array}$ & 5,225 & 89.3 & 2,884 & 89.1 & 1,596 & 89.2 & 745 & 90.4 & $<0.0001$ \\
\hline $\begin{array}{l}\text { NO } \mathrm{H} / \mathrm{O} \\
\text { diabetes }\end{array}$ & 29,634 & 70.9 & 8,332 & 75.4 & 10,305 & 70.5 & 10,727 & 66.6 & \\
\hline $\begin{array}{l}\text { Fasting } \\
\text { glucose }\end{array}$ & & & & ,347 & $\mathbf{n}=4$ & 04 & $n=$ & 70 & \\
\hline
\end{tabular}


Table 5: Documentation of Risk Factors in 47,628 Patients in I 2 Primary Care Clinics Stratified by BMI Category and History of CVD or Diabetes (Continued)

\begin{tabular}{|c|c|c|c|c|c|c|c|c|c|}
\hline $\begin{array}{l}\mathrm{H} / \mathrm{O} \\
\text { diabetes }\end{array}$ & 2,736 & 46.8 & 1,619 & 50.0 & 812 & 45.4 & 305 & 37.0 & 0.003 \\
\hline $\begin{array}{l}\text { NO H/O } \\
\text { diabetes }\end{array}$ & 10,685 & 25.6 & 3,728 & 33.7 & 3,992 & 27.3 & 2,965 & 18.4 & \\
\hline $\begin{array}{l}\text { All } 3 \text { risk } \\
\text { factors }\end{array}$ & & \multicolumn{3}{|c|}{$n=8,247$} & \multicolumn{2}{|c|}{$n=8,797$} & \multicolumn{2}{|c|}{$n=6,986$} & \\
\hline $\begin{array}{l}\mathrm{H} / \mathrm{O} \\
\text { diabetes }\end{array}$ & 3,936 & 67.3 & 2,197 & 67.9 & 1,240 & 69.3 & 499 & 60.6 & 0.001 \\
\hline $\begin{array}{l}\text { NO H/O } \\
\text { diabetes }\end{array}$ & 20,094 & 48.1 & 6,050 & 54.7 & 7,557 & 51.7 & 6,487 & 40.3 & \\
\hline
\end{tabular}

P-value compares homogeneity of odds ratios across groups. CVD = Cardiovascular Disease, BMI = Body Mass Index (weight in kilograms/height in meters $\left.^{2}\right), \mathrm{BP}=$ Blood Pressure, $\mathrm{LDL}=$ low density lipoprotein cholesterol, $\mathrm{HDL}=$ high density lipoprotein cholesterol. All 3 risk factors documented $=$ documentation of BP + LDL + casual OR fasting glucose. Numbers and percentages in table reflect percentage of risk factor documented by BMI type in patients either with or without a history of CVD or DM (i.e., I,93I = 73\% of 2,647 patients who are obese with BP documented with a history of CVD).

strated more variation in risk factor documentation and control by BMI category. At least two recent studies corroborate these data. Melamed et al measured BMI in 289 patients in seven family practice clinics in Israel, and found that BMI was documented in only half of obese patients and 39\% of overweight patients, and that patients with other chronic medical conditions were more likely to have BMI documented than those without documented comorbidities [30]. Waring et al looked at 2,330 overweight and obese patients included in the Cholesterol Education and Research Trial, and found increased odds of overweight or obesity management in relation to weight-related comorbidities for those with moderate or severe obesity [31].

Risk factor control appears to be related to a previously diagnosed risk factor and not to obesity. These findings become even more relevant in light of recent studies that demonstrate increased CVD risk in patients who are overweight and obese compared to normal weight patients, independent of hypertension and hypercholesterolemia [32]. This implies an important need to recognize overweight and obesity, ideally using a simple technique such as BMI, in order to enhance CVD and diabetes complications prevention. Our findings suggest that PCPs are aware of CVD, diabetes, and obesity as strongly tied risk factors, but that they may not recognize obesity as a risk factor for morbidity and mortality independent of these other comorbidities.

\section{Limitations}

Our results must be interpreted with some limitations in mind. This is clinical, not research, data, which naturally suffers from information that is missing and inconsistent in its recording. We carefully addressed missingness with multiple methods of ascertaining exposures, and addressed inconsistencies in data recording by removal of clinically illogical extreme outliers. Evaluation of BMI documentation rates, with the inherent missing data, was a goal of our study. Furthermore, despite its limitations, evaluation of clinical data is a strength of this study, in that it provides a glimpse into current obesity care and insights into improving this practice. Although our data were derived from a single academic health care network, the sites included a representative mixture of urban, suburban, and hospital-based practices, making our findings generalizable and potentially replicable. Another important strength of our study is the use of a long-standing, widely used EHR encompassing all aspects of patient care from a large network of diverse clinics and patient populations. EHRs, while not a perfect tool due to the potential for improperly entered or overlooked data, have great potential for research, with studies showing that EHRs have potential for increasing documentation and treatment of obese patients [33]. Finally while there were differences seen in the percentages of documentation of risk factors, this may be due mainly to test indication, whereby certain tests such as cholesterol levels are more likely to be ordered on most patients than fasting glucose. However, our overall documentation numbers were large enough to yield consistent results across BMI categories.

\section{Conclusions}

It is well-accepted that intentional weight loss mitigates many of the risk factors associated with obesity. Despite rising rates of obesity, physicians appear not to routinely assess BMI during office visits [34]. According to the NCQA, multiple organizations recommend measuring BMI as part of the routine physical examination $[16,9,10,14,15]$. Treatment recommendations for obesity depend on ascertainment of BMI and complications of obesity. Therefore, screening for BMI and comorbidities could change patient management. In light of new studies implicating overweight and obesity as independent risk factors for CVD, recognition of BMI becomes even more important in the primary care setting. We examined a large, diverse primary care network to evaluate current care and found that EHRs will be a useful tool to evaluate 
Table 6: Control of Risk Factors in 47,628 Patients in 12 Primary Care Clinics Stratified by BMI Category and History of CVD or Diabetes

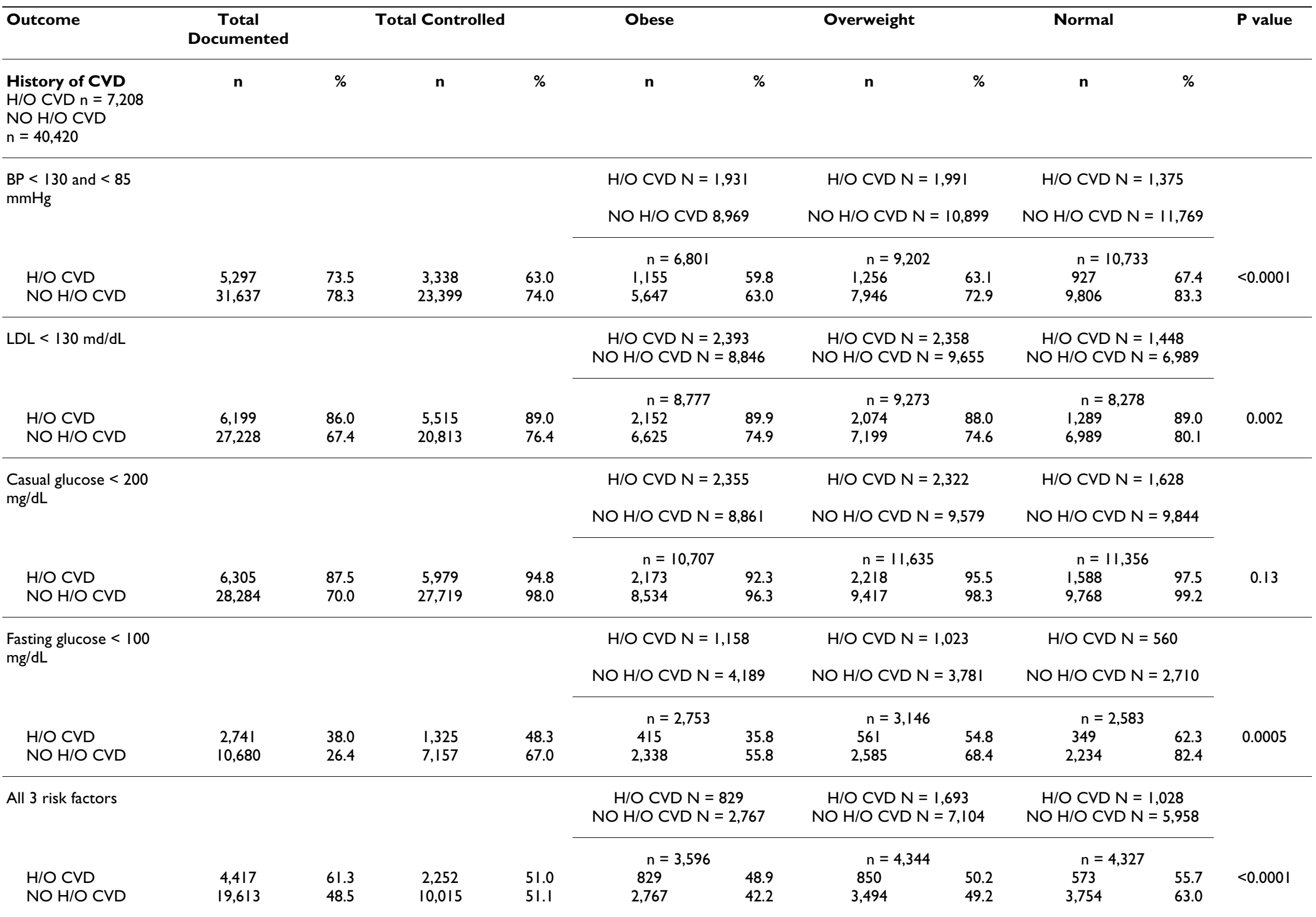


5,851

$\mathrm{NO} \mathrm{H} / \mathrm{O}$ diabetes $\mathrm{n}=$

41,777

$\mathrm{BP}<130$ and $<85$

$\mathrm{mmHg}$
$\mathrm{H} / \mathrm{O}$ diabetes $\mathrm{N}=2,447$

$\mathrm{NO} \mathrm{H} / \mathrm{O}$ diabetes 8,453
$\mathrm{H} / \mathrm{O}$ diabetes $\mathrm{N}=1,366$

$\mathrm{H} / \mathrm{O}$ diabetes $\mathrm{N}=585$

$\mathrm{NO} H / O$ diabetes $\mathrm{N}=11,524 \mathrm{NO} H / O$ diabetes $\mathrm{N}=12,559$

\begin{tabular}{|c|c|c|c|c|c|c|c|c|c|c|c|}
\hline & & & & & $\mathrm{n}=$ & & $\mathrm{n}=$ & & $\mathrm{n}=\mathrm{I}$ & & \\
\hline $\mathrm{H} / \mathrm{O}$ diabetes & $\begin{array}{l}4,398 \\
25,536\end{array}$ & 75.2 & 2,775 & 63.1 & 1,476 & 60.3 & $\begin{array}{l}919 \\
9792\end{array}$ & $\begin{array}{l}67.3 \\
719\end{array}$ & $\begin{array}{l}380 \\
1832\end{array}$ & 65.0 & $<0.0001$ \\
\hline
\end{tabular}

$\mathrm{DL}<130 \mathrm{md} / \mathrm{dL}$

$\mathrm{H} / \mathrm{O}$ diabetes $\mathrm{N}=2,963$

$\mathrm{H} / \mathrm{O}$ diabetes $\mathrm{N}=1,617$

$\mathrm{H} / \mathrm{O}$ diabetes $\mathrm{N}=705$

NO H/O diabetes $\mathrm{N}=8,276 \quad \mathrm{NO} H / O$ diabetes $\mathrm{N}=10,396 \quad$ NO H/O diabetes $\mathrm{N}=9,470$

\begin{tabular}{|c|c|c|c|c|c|c|c|c|c|c|c|}
\hline & & & & & $\mathrm{n}=$ & & $\mathrm{n}=$ & & $\mathrm{n}=$ & & \\
\hline $\begin{array}{l}\mathrm{H} / \mathrm{O} \text { diabetes } \\
\mathrm{NO} \mathrm{H} / \mathrm{O} \text { diabetes }\end{array}$ & $\begin{array}{c}5,285 \\
28,142\end{array}$ & $\begin{array}{l}90.3 \\
67.4\end{array}$ & $\begin{array}{c}4,746 \\
21,583\end{array}$ & $\begin{array}{l}89.8 \\
76.7\end{array}$ & $\begin{array}{l}2,635 \\
6,143\end{array}$ & $\begin{array}{l}88.9 \\
74.2\end{array}$ & $\begin{array}{l}1,462 \\
7,811\end{array}$ & $\begin{array}{l}90.4 \\
75.1\end{array}$ & $\begin{array}{c}649 \\
7,629\end{array}$ & $\begin{array}{l}92.1 \\
80.6\end{array}$ & 0.57 \\
\hline
\end{tabular}

Casual glucose $<200$

$\mathrm{H} / \mathrm{O}$ diabetes $\mathrm{N}=2,884$

$\mathrm{H} / \mathrm{O}$ diabetes $\mathrm{N}=1,596$

$\mathrm{NO} H / \mathrm{O}$ diabetes $\mathrm{N}=8,332 \quad \mathrm{NO} \mathrm{H} / \mathrm{O}$ diabetes $\mathrm{N}=10,305 \quad \mathrm{NO} H / \mathrm{O}$ diabetes $\mathrm{N}=10,727$

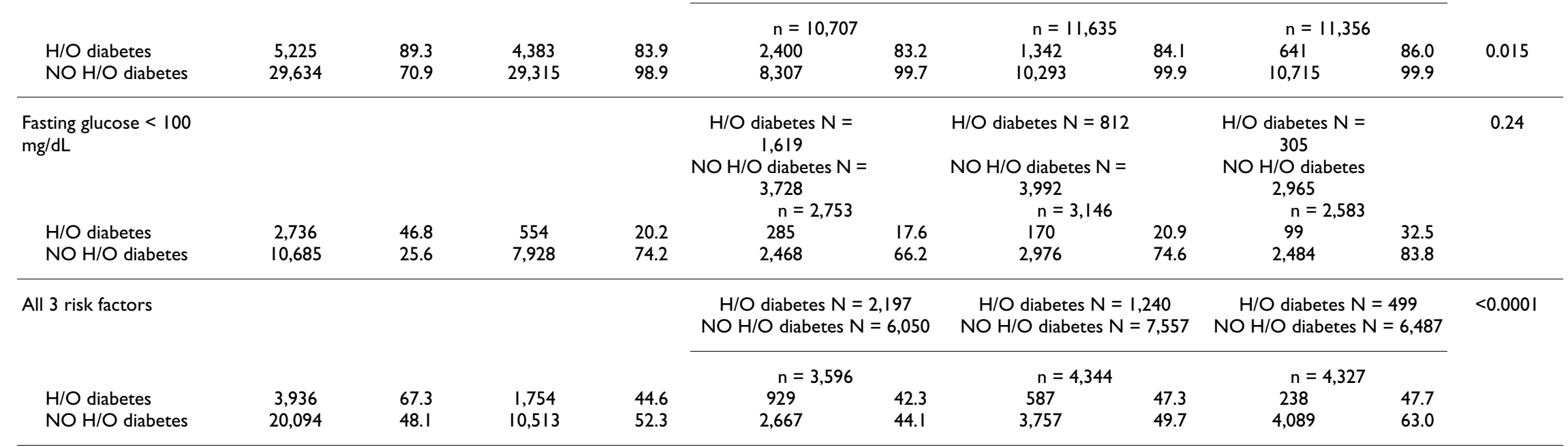

P-value compares homogeneity of the odds ratios across groups. CVD $=$ Cardiovascular Disease, $\mathrm{BMI}=$ Body Mass Index (weight in kilograms/height in meters ${ }^{2}$ ), BP $=\mathrm{Blood}$ Pressure, $\mathrm{LDL}=\mathrm{Low}$ density lipoprotein cholesterol, $\mathrm{HDL}=$ High density lipoprotein cholesterol. Risk factor control rates are from patients with risk factors documented. Numbers and percentages in table reflect percentage of risk factor documented by BMI type in patients either with or without a history of CVD or DM (i.e., I,93I = 73\% of 2,647 patients who are obese with BP documented with a history of CVD). All 3 risk factors controlled = control of BP + LDL + casual OR fasting glucose. Documentation or control of all 3 risk factors defined as BP, LDL, and fasting or casual glucose below the thresholds indicated. 
BMI assessment. We demonstrate substantial opportunities for improvement in the assessment and control of adiposity and associated risk factors that are needed to address the US obesity epidemic.

\section{Abbreviations}

(ATP III): Adult Treatment Panel III; (BP): Blood Pressure; (BMI): Body Mass Index; (CVD): Cardiovascular disease; (CDC):Centers for Disease Control; (EHR): Electronic Health Record; (HEDIS): Healthcare Effectiveness Data and Information Set; (ICD-9): International Classification of Diseases, Ninth Revision; (LDL): Low-density Lipoprotein; (MGH): Massachusetts General Hospital; (NCQA): National Committee for Quality Assurance; (NHLBI): National Heart, Lung, and Blood Institute; (NIDDK): National Institute of Diabetes and Digestive and Kidney Diseases; (NW): Normal weight; (OB): Obese; (OW): Overweight; (PBRN): Practice-Based Research Network; (PCP): Primary Care Physician; (RPDR): Research Patient Data Repository; (US): United States.

\section{Competing interests}

The authors declare that they have no competing interests.

\section{Authors' contributions}

SR helped to conceive the study, developed the study design, performed the statistical analysis, and drafted the manuscript. AT assisted with data retrieval and performed the natural language processing abstraction. RG participated in the design of the study and assisted with data retrieval. JM helped to conceive the study design, assisted with data retrieval, assisted with the statistical analysis, and assisted with editing the manuscript. All authors read and approved the final manuscript.

\section{Acknowledgements}

We thank Peter Shrader and Amy Cohen for their assistance with the analysis, and Daniel Singer, M.D., for review and comment on an earlier draft of the manuscript. Dr. Rose was supported by an Institutional National Research Service Award \#5 T32 HPI I00 I- 19. Dr. Grant was supported by an NIDDK Career Development Award (K23 DK067452). Dr. Meigs was supported by NIDDK K24 DK080 I40. Dr. Meigs currently has research grants from GlaxoSmithKline and sanofi-aventis, and has consulting agreements with GlaxoSmithKline, sanofi-aventis, Interleukin Genetics, Kalypsis, and Outcomes Science. This work has been presented in poster form at the New England Regional Society of General Internal Medicine Conference in March of 2008, the Massachusetts Medical Society Poster Symposium in April of 2008, where it was the Second Prize Winner for Clinical Research, the Massachusetts General Hospital Clinical Research Day in May of 2008, and the Obesity Society Annual Meeting on October 6, 2008.

\section{References}

I. Pi-Sunyer F: Medical hazards of obesity. Ann Intern Med 1993, I 19 (7 pt 2):655-60.

2. Diabetes Prevention Program Research Group: Reduction in the incidence of type 2 diabetes with lifestyle intervention or metformin. NEJM 2002, 346:393-403.

3. Mehotra C, Naimi T, Serdula M, Bolen J, Pearson K: Arthritis, body mass index, and professional advice to lose weight: implica- tions for clinical medicine and public health. Am J Prev Med 2004, 27(I):16-2I.

4. Lopez-Jimenez F, Malinski M, Gutt M, Sierra-Johnson J, Aude $Y$, Rimawi AA, Mego PA, Thomas RJ, Allison TG, Kirby B, Hughes-Borst $B$, Somers VK: Recognition, diagnosis, and management of obesity after myocardial infarction. International journal of obesity 2005, 29:|37-|4|.

5. Buse J, Ginsberg H, Bakris G, Clark N, Costa F, Eckel R, Fonseca V, Gerstein H, Grundy S, Nesto R, Pignone M, Plutzky J, Porte D, Redberg R, Stitzel K, Stone N: Primary prevention of cardiovascular diseases in people with diabetes mellitus: a scientific statement from the American Heart Association and the American Diabetes Association. Circulation 2007, I I5: I I4- 26.

6. Anderson J, Kendall C, Jenkins D: Importance of weight management in type 2 diabetes: review with meta-analysis of clinical studies. Journal of the American college of nutrition 2003, 22(5):331-339.

7. Douketis JD, Feightner JW, Attia J, Feldman WF, Canadian Task Force on Preventive Health Care: Periodic health examination, 1999 update: I. Detection, prevention and treatment of obesity. CMAJ 1999, 160(4):.

8. Barlow SE, Dietz WH: Obesity evaluation and treatment: expert committee recommendations. Pediatrics 1998, 102:e29.

9. U.S. Preventive Services Task Force: Screening for obesity in adults: recommendations and rationale. Annals of internal medicine 2003, 139(I I):930-932

10. Executive summary of the clinical guidelines on the identification, evaluation, and treatment of overweight and obesity in adults 1998 [http://www.ncbi.nlm.nih.gov/bookshelf/ br.fcgi?book=obesity]. Accessed May 29, 2007

II. Screening and interventions to prevent obesity in adults 2003 [http://www.ahrq.gov/clinic/USpstf/uspsobes.htm]. Accessed May 14, 2008

12. Nawaz H, Katz DL: American College of Preventive Medicine practice policy statement weight management counseling of overweight adults. Am J Prev Med 200I, 2 I (I):73-78.

13. Wylie-Rosett J, Albright AA, Apovian C, Clark NG, Delahanty L, Franz MJ, Hoogwerf B, Kulkarni K, Lichtenstein AH, Mayer-Davis E, Mooradian AD, Wheeler M: 2006-2007 American Diabetes Association nutrition recommendations: issues for practice translation. Journal of the American Dietetic Association 2007, 107(8): 1296-1304.

14. Prevention and management of obesity (mature adolescents and adults) [http://www.guideline.gov/summary/
[ pdf.aspx? doc id=10226\&stat=1 \&string=]. Accessed May 14, 2008

15. Identification, evaluation, and treatment of overweight and obesity in the adult [http://www.mqic.org/pdf/obesity 05.pdf]. Accessed May 14, 2008

16. Body Mass Index (BMI) Assessment for Adults (BAA) 2008 [http://www.ncqa.org/Portals/0/PublicComment/HEDIS2009/ BAA Specs and Workup PDF.pdf]. Accessed April 25, 2008

17. HEDIS 2009 Public Comment 2008 [http://www.ncqa.org/tabid/ 661/Default.aspx]. Accessed July 30, 2008

18. Hivert MF, Grant RW, Shrader P, Meigs JB: Identifying primary care patients at risk for future diabetes and cardiovascular disease using electronic health records. BMC Health Serv Res 2009, 9:170.

19. Turchin A, Pendergrass ML, Kohane IS: DITTO - A tool for identification of patient cohorts from the text of physician notes in the electronic medical record. Proc AMIA Symp 2005:744-8.

20. Turchin A, Kolatkar NS, Grant RW, Makhni EC, Pendergrass ML, Einbinder JS: Using regular expressions to abstract blood pressure and treatment intensification information from the text of physician notes. JAMIA 2006, I3(6):69I-695.

21. Defining Overweight and Obesity 2007 [http://www.cdc.gov/ nccdphp/dnpa/obesity/defining.htm]. Accessed 5/28/08

22. Metabolic Syndrome 2007 [http://www.americanheart.org/pre senter.jhtml? identifier=534]. (Accessed 5/28/08)

23. ATP III Guidelines At-A-Glance Quick DeskReference 200 I [http://www.nhlbi.nih.gov/guidelines/cholesterol/atglance.pdf]. Accessed 5/28/08

24. Meigs JB, Cupples LA, Wilson PW: Parental transmission of type 2 diabetes: the Framingham Offspring Study. Diabetes 2000, 49( I 2):220I-7.

25. DeFaria Yeh D, Freeman MW, Meigs JB, Grant RW: Risk factors for coronary artery disease in patients with elevated high-den- 
sity lipoprotein cholesterol. American Journal of Cardiology 2007, 99(I): $1-4$

26. Grant RW, Cagliero E, Sullivan CM, Dubey AK, Estey GA, Weil EM, Gesmundo J, Nathan DM, Singer DE, Chueh HC, Meigs JB: A controlled trial of population management: diabetes mellitus: putting evidence into practice (DM-PEP). Diabetes Care 2004, 27(1 0):2299-2305.

27. Lemay CA, Cashman S, Savageau J, Fletcher K, Kinney R, Long-Middleton $E$ : Underdiagnosis of obesity at a community health center. J Am Board Fam Pract 2003, I6(1): 14-2I.

28. Rifas-Shiman SL, Forman JP, Lane K, Caspard H, Gillman MW: Diabetes and lipid screening among patients in primary care: a cohort study. BMC health services research 2008, 8(25):.

29. Molenaar EA, Hwang S, Vasan RS, Grobbee DE, Meigs JB, D'Agostino RB, Levy D, Fox CS: Burden and rates of treatment and control of cardiovascular disease risk factors in obesity: the Framingham heart study. Diabetes care 2008, 3 I (7): 1367-72.

30. Melamed OC, Nakar S, Vinker S: Suboptimal identification of obesity by family physicians. Am J Manag Care 2009, I5(9):619-24.

31. Waring ME, Roberts MB, Parker DR, Eaton CB: Documentation and management of overweight and obesity in primary care. J Am Board Fam Med 2009, 22(5):544-52.

32. Bogers RP, Bemelmans WJ, Hoogenveen RT, Boshuizen HC, Woodward M, Knekt P, van Dam RM, Hu FB, Visscher TL, Menotti A, Thorpe RJ Jr, Jamrozik K, Calling S, Strand BH, Shipley MJ, for the BMICHD Collaboration Investigators: Association of overweight with increased risk of coronary heart disease partly independent of blood pressure and cholesterol levels: a metaanalysis of 21 cohort studies including more than 300,000 persons. Arch Intern Med 2007, 167(16): 1720-8.

33. Bordowitz R, Morland K, Reich D: The use of an electronic medical record to improve documentation and treatment of obesity. Fam Med 2007, 39(4):274-9.

34. Jackson J, Doescher M, Saver B, Hart L: Trends in professional advice to lose weight among obese adults. J gen intern med 2005, 20:8|4-8.

\section{Pre-publication history}

The pre-publication history for this paper can be accessed here:

http://www.biomedcentral.com/1472-6963/9/236/pre

pub

Publish with Bio Med Central and every scientist can read your work free of charge

"BioMed Central will be the most significant development for disseminating the results of biomedical research in our lifetime. "

Sir Paul Nurse, Cancer Research UK

Your research papers will be:

- available free of charge to the entire biomedical community

- peer reviewed and published immediately upon acceptance

- cited in PubMed and archived on PubMed Central

- yours - you keep the copyright
BioMedcentral 